\title{
PENGENAAN PAJAK PERTAMBAHAN NILAI PADA ONLINE MARKETPLACE TOKOPEDIA
}

\author{
Aufa Yudhistira \\ aufayudhistira@gmail.com, Politeknik Keuangan Negara STAN
}

\begin{abstract}
The purpose of the study is to understand the e-commerce business model and process in the Tokopedia online marketplace and review the treatment of the imposition of Value Added Tax (VAT) on goods delivery transactions that occur in the Tokopedia online marketplace. The research method used is descriptive qualitative. The result of the research is that Tokopedia earns income from premium features used by merchants, not from purchasing activities made by buyers. Events when merchants use Tokopedia's premium features are events that are subject to VAT. An event when a merchant with PKP status delivers goods to the Buyer, VAT is payable. Invoice or payment details received by the buyer that are not listed have been subject to VAT on the purchase of goods. The buyer makes a payment to the escrow account which will then be forwarded to the merchant, so the escrow account is required to collect VAT from the buyer. Events when a merchant sends goods to a buyer using a courier service are events that are VAT payable. The invoice or payment details received by the buyer that are not listed have been subject to VAT for the use of goods delivery services via courier.
\end{abstract}

Keywords : E-commerce, Tokopedia, Value Added Tax

\begin{abstract}
Abstrak
Tujuan penelitian adalah memahami model serta proses bisnis e-commerce pada online marketplace Tokopedia dan meninjau perlakuan pengenaan Pajak Pertambahan Nilai (PPN) atas transaksi penyerahan barang yang terjadi di online marketplace Tokopedia. Metode penelitian yang digunakan adalah kualitatif deskriptif. Hasil penelitian adalah Tokopedia mendapatkan penghasilan dari fitur premium yang digunakan oleh merchant, bukan dari kegiatan pembelian yang dilakukan oleh pembeli. Peristiwa saat merchant menggunakan fitur premium Tokopedia merupakan peristiwa yang terutang PPN. Peristiwa saat merchant yang berstatus PKP menyerahkan barang kepada Pembeli terutang PPN. Invoice atau rincian pembayaran yang diterima pembeli tidak tercantum telah dikenakan PPN atas pembelian barang. Pembeli melakukan pembayaran kepada escrow account yang selanjutnya akan diteruskan kepada merchant, sehingga escrow account wajib memungut PPN dari pembeli. Peristiwa saat merchant mengirimkan barang kepada pembeli menggunakan jasa kurir merupakan peristiwa yang terutang PPN. Invoice atau rincian pembayaran yang diterima pembeli tidak tercantum telah dikenakan PPN atas pemanfaatan jasa pengiriman barang melalui kurir.
\end{abstract}

Kata kunci : E-commerce, Pajak pertambahan nilai, Tokopedia

\section{PENDAHULUAN}

Dewasa ini model bisnis jual dan beli semakin berkembang pesat. Dahulu transaksi jual dan beli masih menggunakan toko fisik. Namun, sekarang sudah menggunakan fasilitas internet sebagai media transaksi. Bisnis e-commerce dapat dengan mudah ditemui dalam kehidupan bermasyarakat, terutama situasi terkini dimana kemajuan teknologi berkembang begitu pesat. Salah satu model transaksi e-commerce adalah melalui online marketplace, yaitu lokasi jual beli produk dimana penjual dan juga konsumen bertemu di suatu website. Penjual akan menjual barangnya di lapak yang sudah disediakan oleh e-commerce dengan konsep online marketplace. Barang yang dijual di online marketplace tersebut kemudian akan diiklankan oleh pihak e-commerce untuk mendapatkan konsumen yang potensial. Kesuksesan e-commerce dengan konsep online marketplace ini ditentukan oleh banyaknya jumlah seller dan juga konsumen yang bergabung di website e-commerce tersebut.

Untuk mendapatkan lapak berjualan, seorang penjual tidak dibebankan biaya sewa. Lantas bagaimana pihak e-commerce online marketplace mendapatkan keuntungan? Pihak $e$ commerce marketplace akan mendapatkan keuntungan dari pihak penjual dengan memanfaatkan iklan premium. Dari sekian banyak online marketplace di Indonesia, Tokopedia dijadikan sebagai objek dalam penelitian ini. Berdasarkan pengamatan, permasalahan muncul ketika menerima invoice, tidak ditemukan adanya pemungutan pajak pertambahan nilai atas 


\section{JURNALKU}

Volume 1 No. 1, Maret 2021

transaksi-transaksi tersebut. Sehingga ingin melakukan peninjauan aspek perpajakan khususnya pajak pertambahan nilai atas transaksi yang terdapat di online marketplace Tokopedia. Namun, penelitian difokuskan permasalahan pada penyerahan barang yang terjadi di online marketplace Tokopedia.

Penelitian terdahulu berdasarkan pengamatan adalah Djufri (2020) yang menghasilkan bahwa penggunaan teknik web scraping dapat digunakan sebagai penggalian potensi pajak. Hal ini berbeda dengan penelitian yang dilakukan terkait dengan pajak pertambahanan nilai pada Tokopedia. Wijaya \& Nirvana (2021) meneliti kewajiban Shopee sebagai pemungut PPN PMSE dan kewajiban sebagai pengusaha kena pajak. Hal ini berbeda dengan penelitian yang dilakukan karena bukan PMSE. Adapun Antariksa (2020) mendapati bahwa merchant dari Tokopedia dan Bukalapak yang berasal dari Jawa Timur sudah patuh terhadap kepatuhan perpajakan. Namun Antariksa (2020) berkesimpulan hanya berdasarkan kuesioner, bukan penilaian kepatuhan perpajakan yang membandingkan kegiatan usaha dengan ketentuan perpajakannya.

Adapun Ridho (2021) meskipun meneliti pajak pertambahan nilai pada e-commerce, namun hanya menghasilkan kesimpulan secara umum bahwa transaksi tersebut dikenakan PPN. Hal ini berbeda dengan yang dilakukan penelitian, di mana akan menjelaskan proses bisnis dan pengenaan pajak pertambahan nilai terhadap seluruh rangkaian bisnis sampai dengan barang berpindah ke konsumen. Sementara itu Nugroho (2016) mengusulkan supaya pemerintah menerapkan $e$-wallet sebagai tempat menampung pajak pertambahan nilai dari sektor $e$ commerce. Sehingga hal ini hanya merupakan usulan terhadap penampungan pembayaran pajak atas suatu transaksi. Berbeda dengan penelitian ini yang menganilisis transaksi online di Tokopedia sehubungan dengan pengenaan pajak pertambahan nilai.

Mogi (2021) melakukan penelitian di mana potensi perpajakan terhadap transaksi $E$ Commerce di Indonesia sangat besar, namun ada beberapa faktor penghambat dalam pengenaan pajak terhadap E-Commerce baik dari faktor hukum faktor pemerintah maupun pelaku usaha online sebagai wajib pajak. Adapun Mulya \& Agatha (2020) meskipun mengkaji penerapan PPN di sektor e-commerce, namun penelitian ini dilakukan secara kuantitatif, jadi tidak menganalisis transaksi dan ketentuan perpajakannya.

Berbeda dengan itu, Sasana (2021) menyatakan bahwa Indonesia masih dimungkinkan melakukan pengenaan PPN atas transaksi e-commerce berdasarkan ketentuan perpajakan, sehingga diharapkan pemerintah agar membuat aturan yang jelas mengenai transaksi $e$ commerce terutama dalam membuat sistem dan prosedur pengenaan PPN atas transaksi $e$ commerce yang didasarkan atas asas kepastian hukum, asas kemudahan dan berbiaya rendah dengan menggunakan bantuan teknologi. Indriyani \& Furqon (2021) meneliti kepatuhan Bukalapak terhadap ketentuan perpajakan yang ada. Tentu saja hal ini berbeda dengan yang dilakukan dalam penelitian ini.

Rachmasariningrum (2020) dalam penelitiannya menunjukkan bahwa untuk memaksimalkan penerimaan pajak dari transaksi online, maka perlu adanya regulasi yang secara khusus diterapkan pada transaksi online dan sistem pengawasan yang solid agar penerimaan pajak dari transaksi online dapat terkumpul secara maksimal. Adapun Fitriandi (2020) mengusulkan agar online marketplace ditetapkan sebagai pemotong PPh final PP 23 Tahun 2018.

Sementara itu Sivia (2019) menjelaskan bahwa PT. XYZ E-commerce di Indonesia yang memiliki platform digital ternyata belum memberikan potensi dan dukungan yang lengkap terhadap penerimaan pajak. Hal ini dikarenakan masih banyak perusahaan e-commerce yang belum menerima dirinya sebagai wajib pajak badan, serta masih banyaknya perusahaan $e$ commerce yang belum memenuhi kewajiban perpajakannya dari platform digital yang dibutuhkan. Oleh karena itu, peran pemerintah khususnya Dirjen Pajak meminta adanya 


\section{JURNALKU}

Volume 1 No. 1, Maret 2021

pengawasan khusus yang bertujuan untuk mengumpulkan potensi pajak dari sektor $e$ commerce. Menjawab penelitian Silvia (2019), maka tujuan penelitian adalah memahami model serta proses bisnis e-commerce pada online marketplace Tokopedia dan meninjau perlakuan pengenaan Pajak Pertambahan Nilai (PPN) atas transaksi penyerahan barang yang terjadi di online marketplace Tokopedia.

\section{KAJIAN TEORI}

\section{Pajak Pertambahan Nilai.}

McNulty (2000, dikutip dalam Wijaya \& Fatimah, 2020) menambahkan bahwa PPN adalah pajak yang dikenakan atas nilai tambah oleh setiap pengusaha kena pajak. Pajak Pertambahan Nilai menurut Pohan (2016, dikutip dalam Wijaya \& Sabina, 2021) berdasarkan legal karakteristiknya merupakan pajak objektif, dalam artian bahwa pengenaan pajak pertama kali memperhatikan objeknya kemudian melihat subjeknya.

Menurut Sukardji (2015), pasal 3A ayat 1 Undang-Undang Nomor 42 Tahun 2009 harus dihubungkan dengan Peraturan Menteri Keuangan yang ditugasi membuat kriteria pengusaha kecil, yaitu Peraturan Menteri Keuangan nomor 68/PMK.03/2010 sebagaimana telah diubah dengan Peraturan Menteri Keuangan nomor 197/PMK.03/2013. Berdasarkan rangkaian pasal-pasal tersebut, definisi PKP dapat dirumuskan sebagai Pengusaha Kena Pajak adalah pengusaha yang melakukan penyerahan BKP dan/atau JKP yang dikenai pajak, dalam satu tahun buku atau bagian tahun buku memperoleh peredaran usaha atau penerimaan usaha melebihi batas maksimum peredaran/penerimaan usaha pengusaha kecil.

\section{E-commerce}

Ekonomi digital menurut Tapscott (1996, dikutip dalam Wijaya \& Utamawati, 2018) adalah kegiatan ekonomi yang didasarkan pada teknologi digital internet dan disebut juga dengan internet economy, digital-based economy, new economy knowledge, atau new economy. Salah satu bagian dari ekonomi digital adalah e-commerce. Menurut Penjelasan Umum Undang-Undang Nomor 11 Tahun 2008 tentang Informasi dan Transaksi Elektronik, $e$ commerce merupakan kegiatan perdagangan melalui sistem elektronik, yaitu suatu kegiatan perdagangan yang dilakukan melalui serangkaian perangkat dan prosedur elektronik yang berfungsi mempersiapkan, mengumpulkan, mengolah, menganalisis, menyimpan, menampilkan, mengumumkan, mengirimkan, dan/atau menyebarkan informasi elektronik. Baum dalam Bagus (2010) menyatakan bahwa e-commerce adalah merupakan satu set dinamis teknologi, aplikasi, dan proses bisnis yang menghubungkan perusahaan, konsumen, dan komunitas tertentu melalui transaksi elektronik dan perdagangan barang, pelayanan, dan informasi yang dilakukan secara elektronik.

\section{METODE}

Penelitian dilakukan dengan menggunakan pendekatan kualitatif deskriptif. Moleong (2010, dikutip dalam Wijaya \& Safira, 2021) menyatakan bahwa penelitian kualitatif bermaksud untuk memahami fenomena tentang apa yang dialami oleh subjek penelitian misalnya perilaku, persepsi, motivasi, tindakan, dan lain-lain secara holistic dan dengan cara deskripsi dalam bentuk kata-kata dan bahasa, pada suatu konteks khusus yang alamiah dan dengan memanfaatkan berbagai metode alamiah. Penelitian menggunakan metode penelitian studi kepustakaan. Metode penelitian kepustakaan adalah metode yang dilaksanakan dengan cara mempelajari sejumlah literatur berupa kajian pustaka, buku, jurnal, berita di media masa dan lainnya untuk memperoleh dasar teoritis mengenai permasalahan yang akan dibahas dalam penelitian ini. 


\section{JURNALKU}

Volume 1 No. 1, Maret 2021

\section{HASIL DAN PEMBAHASAN} Gambaran Umum

E-commerce terdiri dari beberapa model bisnis. Setiap negara memiliki model bisnis $e$ commerce yang berbeda, tergantung dari pasar yang ada. Menurut Surat Edaran Direktur Jenderal Pajak Nomor SE-62/PJ/2013, terdapat 4 (empat) model transaksi e-commerce, yaitu (1) Online marketplace adalah kegiatan usaha berupa Toko Internet di Mal Internet sebagai tempat Online Marketplace Merchant menjual barang dan/atau jasa. Beberapa contoh online marketplace yang ada di Indonesia adalah Tokopedia, BukaLapak, dan Lamido. (2) Classified ads adalah kegiatan menyediakan tempat dan/atau waktu untuk memajang content (teks, grafik, video penjelasan, informasi, dan lain-lain) barang dan/atau jasa bagi Pengiklan untuk memasang iklan yang ditujukan kepada Pengguna Iklan melalui situs yang disediakan oleh Penyelenggara Classified Ads. Beberapa contoh classified ads yang ada di Indonesia adalah Kaskus, Berniaga, dan OLX. (3) Daily deals merupakan kegiatan menyediakan tempat kegiatan usaha berupa situs daily deals sebagai tempat Daily Deals Merchant menjual barang dan/atau jasa kepada Pembeli dengan menggunakan voucher sebagai sarana pembayaran. Beberapa contoh daily deals yang ada di Indonesia adalah LivingSocial, Groupon Disdus, dan Lakupon. (4) Online retail adalah kegiatan menjual barang dan/atau jasa yang dilakukan oleh Penyelenggara Online Retail kepada Pembeli di situs online retail. Beberapa contoh online retail yang ada di Indonesia adalah Blibli dan Lazada.

Berdasarkan Lampiran Surat Edaran Direktur Jenderal Pajak Nomor SE-62/PJ/2013 Tentang Penegasan Ketentuan Perpajakan atas Transaksi E-commerce, online marketplace memiliki deskripsi sebagai berikut (1) Mal Internet adalah situs perbelanjaan yang berbasis internet yang terdiri dari beberapa Toko Internet yang dikelola oleh Penyelenggara Online Marketplace. (2) Toko Internet adalah bagian dari Mal Internet yang ditawarkan oleh Penyelenggara Online Marketplace kepada Online Marketplace Merchant sebagai tempat kegiatan usaha. (3) Penyelenggara Online Marketplace adalah pihak yang menjalankan kegiatan usaha Mal Internet. (4) Online Marketplace Merchant adalah pihak yang membuka dan mengoperasikan Toko Internet untuk melakukan penjualan barang dan/atau jasa di Toko Internet melalui Mal Internet. (5) Pembeli adalah pihak yang melakukan pembelian barang dan/atau jasa dari Online. (6) Marketplace Merchant di Toko Internet melalui Mal Internet. (7) Perjanjian adalah kontrak yang ditandatangani oleh Online Marketplace Merchant dan Penyelenggara Online Marketplace yang isinya dapat mengatur tentang syarat dan ketentuan yang berlaku tentang tata cara pengoperasian Toko Internet melalui Mal Internet dan tata cara penjualan barang dan/atau jasa di Toko Internet melalui Mal Internet. (8) Monthly Fixed Fee yang dikenal juga dengan istilah Rent Fee, Registration Fee, Fixed Fee, atau Subscription Fee adalah imbalan atas jasa penyediaan tempat dan/atau waktu untuk memajang content (teks, grafik, video penjelasan, informasi, dan lain-lain) barang dan/atau jasa dan melakukan penjualan di Toko Internet melalui Mal Internet. (9) Per Sale Fee adalah sejumlah uang yang dibayarkan oleh Online Marketplace Merchant kepada Penyelenggara Online Marketplace sebagai komisi atas jasa perantara pembayaran atas penjualan barang dan/atau jasa yang dilakukan oleh Online Marketplace Merchant di Toko Internet melalui Mal Internet. Per Sale Fee umumnya berupa persentase atas nilai transaksi penjualan dan dipotong dari nilai transaksi. (10) Point Fee adalah bonus/reward dalam bentuk poin yang memiliki nilai uang, yang diberikan oleh Online Marketplace Merchant kepada Pembeli atas pembelian barang dan/atau jasa di Toko Internet melalui Mal Internet. Point Fee dikelola oleh Penyelenggara Online Marketplace dan hanya dapat digunakan untuk melakukan pembelian barang dan/atau jasa di Toko Internet melalui Mal Internet tersebut. Point Fee umumnya berupa persentase atas nilai transaksi penjualan dan dipotong oleh Penyelenggara Online Marketplace dari nilai transaksi penjualan tersebut. (11) Pembeli melakukan pembayaran atas transaksi yang dilakukan melalui 


\section{JURNALKU}

Volume 1 No. 1, Maret 2021

Escrow Account yang ditetapkan oleh Penyelenggara Online Marketplace. (12) Online Marketplace Merchant mengirimkan barang dan/atau jasa kepada Pembeli baik dengan menggunakan fasilitas pengiriman sendiri atau melalui penyedia jasa pengiriman setelah menerima pemberitahuan dari Penyelenggara Online Marketplace bahwa Penyelenggara Online Marketplace telah menerima pembayaran dari Pembeli. (13) Setiap transaksi penjualan barang dan/atau jasa di Toko Internet melalui Mal Internet dilakukan antara Pembeli dengan Online Marketplace Merchant sehingga Penyelenggara Online Marketplace tidak bertanggungjawab atas setiap kehilangan atau kerugian pasca transaksi penjualan barang dan/atau jasa.

Pihak-pihak yang terkait dengan transaksi e-commerce model bisnis online retail adalah (1) Penyelenggara Online Marketplace, yang bertugas menyediakan Mal Internet sebagai tempat Online Marketplace Merchant menjual barang-barang kepada Pembeli. (2) Online Marketplace Merchant. Merchant bertugas memasang foto berbagai barang yang dijual Merchant di Mal Internet dengan menampilkan deskripsi yang lengkap serta harga dari barang tersebut. (3) Pembeli harus mendaftarkan akun terlebih dahulu untuk dapat membeli barang di online marketplace. Pembeli dapat mengikuti prosedur pembayaran yang sudah ada setelah menentukan barang yang akan dibeli. Pembeli diminta untuk memberikan ulasan kepada Merchant setelah barang diterima. (4) Escrow Account ditunjuk oleh Penyelenggara sebagai pihak ketiga yang netral dan bertindak sebagai pemelihara dana-dana sepanjang proses penyerahan hak milik dari Merchant ke Pembeli. (5) Kurir. Penyedia jasa pengiriman barang yang selanjutnya disebut Kurir, bertugas mengirimkan barang dari Merchant kepada Pembeli.

Tokopedia merupakan salah satu situs online marketplace di Indonesia. Berikut adalah proses bisnis online marketplace sesuai dengan Lampiran Surat Edaran Direktorat Jenderal Pajak Nomor SE-62/PJ/2013 tentang Penegasan Ketentuan Perpajakan atas Transaksi Ecommerce, yaitu (1) Online Marketplace Merchant menawarkan barang dan/atau jasa yang akan dijual dengan mengunggah data dan/atau informasi terkait barang dan/atau jasa yang akan dijual di Toko Internet melalui Mal Internet. (2) Penyelenggara Online Marketplace melakukan verifikasi dan menampilkan data dan/atau informasi terkait barang dan/atau jasa yang akan dijual di Toko Internet melalui Mal Internet. (3) Pembeli melakukan pemesanan di Toko Internet melalui Mal Internet. Untuk memesan barang dan/atau jasa di Mal Internet, beberapa Penyelenggara Online Marketplace mensyaratkan Pembeli untuk mendaftarkan diri. (4) Penyelenggara Online Marketplace mengeluarkan rincian transaksi beserta jumlah yang harus dibayar oleh Pembeli di Toko Internet melalui Mal Internet (contohnya jenis barang, harga barang, jumlah barang, metode pembayaran, mekanisme pengiriman, dan biaya-biaya terkait lainnya). (5) Pembeli melakukan pembayaran melalui Escrow Account yang telah ditetapkan oleh Penyelenggara Online Marketplace. (6) Penyelenggara Online Marketplace di Toko Internet melalui Mal Internet menyampaikan notifikasi kepada Online Marketplace Merchant untuk melakukan pengiriman barang dan/atau jasa kepada Pembeli. (7) Online Marketplace Merchant melakukan pengiriman barang dan/atau jasa kepada Pembeli, baik dengan menggunakan fasilitas pengiriman sendiri atau melalui penyedia jasa pengiriman. Selanjutnya, Online Marketplace Merchant juga mengirimkan notifikasi kepada Penyelenggara Online Marketplace untuk memberitahu bahwa Online Marketplace Merchant telah melakukan pengiriman barang dan/atau jasa kepada Pembeli.

Proses bisnis online marketplace menurut Lampiran Surat Edaran Direktorat Jenderal Pajak Nomor SE-62/PJ/2013 tentang Penegasan Ketentuan Perpajakan atas Transaksi Ecommerce. Untuk dapat lebih memahami tentang proses bisnis Tokopedia, digambarkan bagan arus sebagai berikut: 


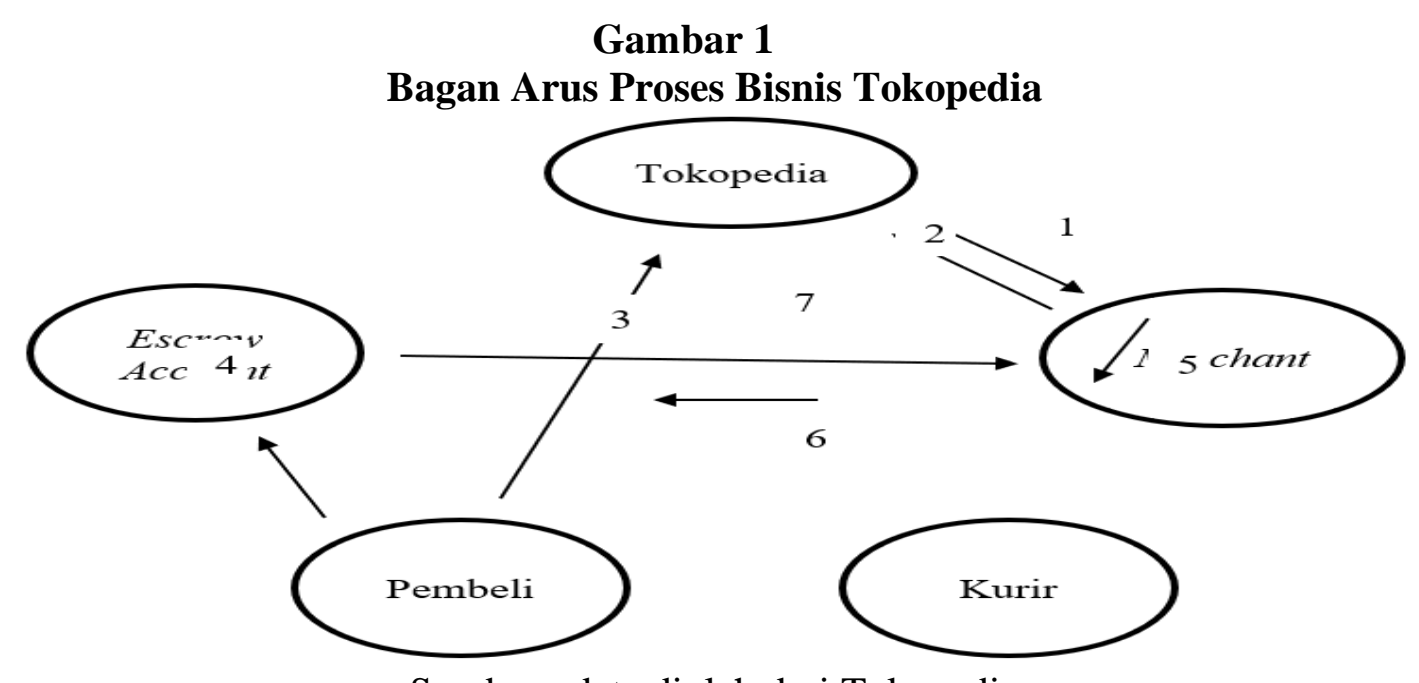

Sumber : data diolah dari Tokopedia

Penjabaran dari setiap angka dalam bagan arus di atas sebagai berikut (1) Tokopedia sebagai Penyelenggara Online Marketplace menyediakan platform berbentuk Mal Internet yang dapat dimanfaatkan Online Marketplace Merchant untuk membuka toko online. (2) Online Marketplace Merchant harus mendaftarkan akun terlebih dahulu untuk dapat membuka toko. Setelah itu, Merchant dapat menambahkan produk yang ingin dijual. (3) Pembeli harus mendaftarkan akun terlebih dahulu untuk dapat membeli barang dari Merchant. (4) Pembeli dapat melakukan pembayaran melalui transfer bank, transfer virtual account, gerai retail, dan lain-lain. Setelah melakukan pembayaran, pembeli harus melakukan verifikasi untuk dapat melanjutkan transaksi. (5) Setelah pembayaran diterima oleh Escrow Account, Merchant dapat mengirimkan paket penjualannya ke Pembeli melalui Kurir yang telah dipilih oleh Pembeli. (6) Kurir mengantarkan paket pembelian kepada Pembeli. Setelah barang sampai ke tangan Pembeli, ia harus melakukan konfirmasi melalui aplikasi Tokopedia sebagai bukti penerimaan. (7) Escrow Account dapat meneruskan pembayaran ke Merchant.

Proses di atas merupakan proses bisnis secara garis besar. Dalam pembahasan berikutnya, akan dirinci lebih lanjut ke dalam beberapa bagan arus proses bisnis. Bagan-bagan tersebut adalah Bagan Arus Proses Bisnis Penyediaan Tempat, Bagan Arus Proses Bisnis Pemesanan Barang, dan Bagan Arus Proses Bisnis Pengiriman Barang.

Bagan Arus Proses Bisnis Penyediaan Tempat.

Berikut adalah bagan arus proses bisnis penyediaan tempat di Tokopedia berdasarkan dengan Lampiran Surat Edaran Direktorat Jenderal Pajak Nomor SE-62/PJ/2013 tentang Penegasan Ketentuan Perpajakan atas Transaksi E-commerce:

Gambar 2 Bagan Arus Proses Bisnis Penyediaan Tempat

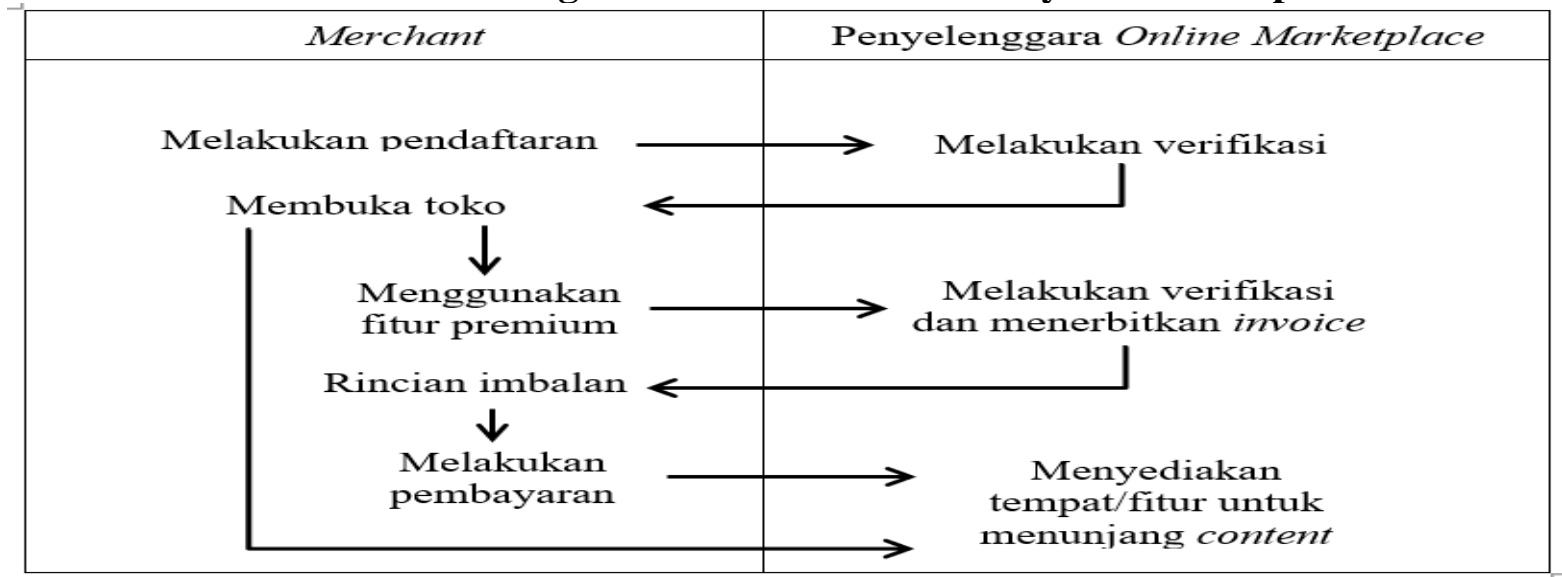

Sumber diolah dari : SE-62/PJ/2013 


\section{JURNALKU}

Volume 1 No. 1, Maret 2021

Menurut website Tokopedia, terdapat dua langkah dalam membuka toko (1) Klik "Buka Toko" pada bagian kiri-atas halaman home. Bisa juga dengan klik ikon "Toko" header menu, lalu pilih "Buka Toko". (2) Isi semua data yang diperlukan dengan lengkap dan benar, seperti: Domain Toko, Informasi Toko, Dukungan Pengiriman, Dukungan Pembayaran, dan Foto profil Toko. Kemudian, klik "Buka Toko".

Dalam aplikasi Tokopedia, Merchant dapat menggunakan fitur premium untuk menggunakan jasa iklan yang ditawarkan Tokopedia. Fitur tersebut adalah Official Store, Gold Merchant dan TopAds. Untuk membuka Official Store, Merchant harus membayar biaya pembukaan toko. Untuk dapat menggunakan fitur Gold Merchant, Merchant harus membayar biaya langganan. Fitur TopAds memiliki sistem kredit saldo sehingga Merchant diharuskan untuk top up sejumlah saldo untuk bisa menggunakan fitur ini.

Bagan Arus Proses Bisnis Pemesanan Barang.

Berikut adalah bagan arus proses bisnis pemesanan barang di Tokopedia sesuai dengan Lampiran Surat Edaran Direktorat Jenderal Pajak Nomor SE-62/PJ/2013 tentang Penegasan Ketentuan Perpajakan atas Transaksi E-commerce:

\section{Gambar III.3}

\section{Bagan Arus Proses Bisnis Penyediaan Tempat}

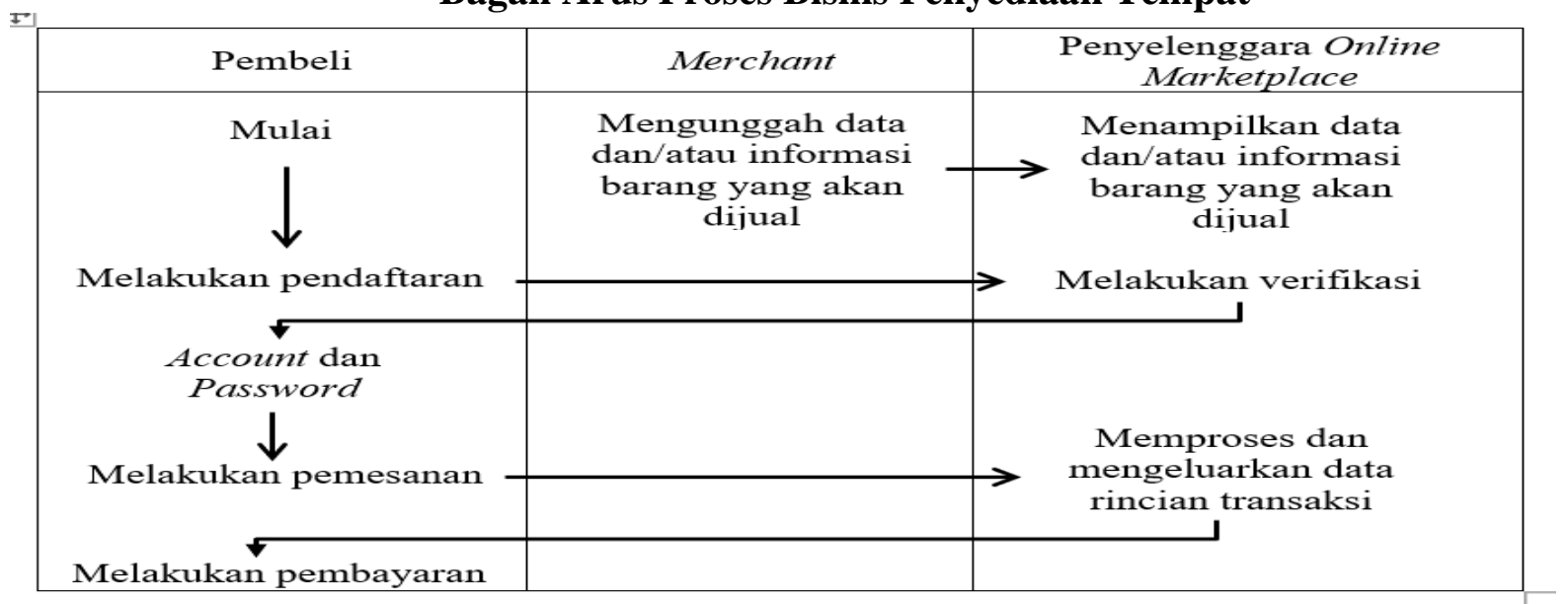

Sumber : SE-62/PJ/2013

Dalam hal pembayaran, Pembeli diberi beberapa pilihan metode pembayaran. Pembayaran dapat dilakukan melalui transfer bank, transfer virtual account, pembayaran instan, kartu kredit, kartu debit, maupun gerai retail. Masing-masing memiliki perlakuan verifikasi yang berbeda. Pembayaran melalui transfer bank memerlukan verifikasi secara manual. Pembayaran melalui transfer virtual account sudah memiliki sistem verifikasi otomatis. Selain kedua metode pembayaran tersebut tidak memerlukan verifikasi.

Setelah pembayaran dilakukan oleh Pembeli, pihak Escrow Account akan mengirimkan notifikasi kepada Tokopedia. Pihak Tokopedia akan menindaklanjuti dengan mengirimkan notifikasi kepada Merchant. Barang dikemas sedemikian rupa oleh Merchant agar Pembeli mendapatkan pelayanan yang memuaskan. Setelah itu Merchant dapat mengirimkan barang tersebut melalui Kurir.

Bagan Arus Proses Bisnis Pengiriman Barang.

Dalam Lampiran Surat Edaran Direktorat Jenderal Pajak Nomor SE-62/PJ/2013 tentang Penegasan Ketentuan Perpajakan atas Transaksi E-commerce, tidak terdapat bagan arus proses bisnis pengiriman barang. Penelitian menggunakan pengamatan untuk membuat bagan tersebut. Bagan tersebut penting karena terdapat peristiwa yang berpotensi terutang Pajak Pertambahan Nilai. Berikut adalah bagan arus proses bisnis pengiriman barang di Tokopedia: 


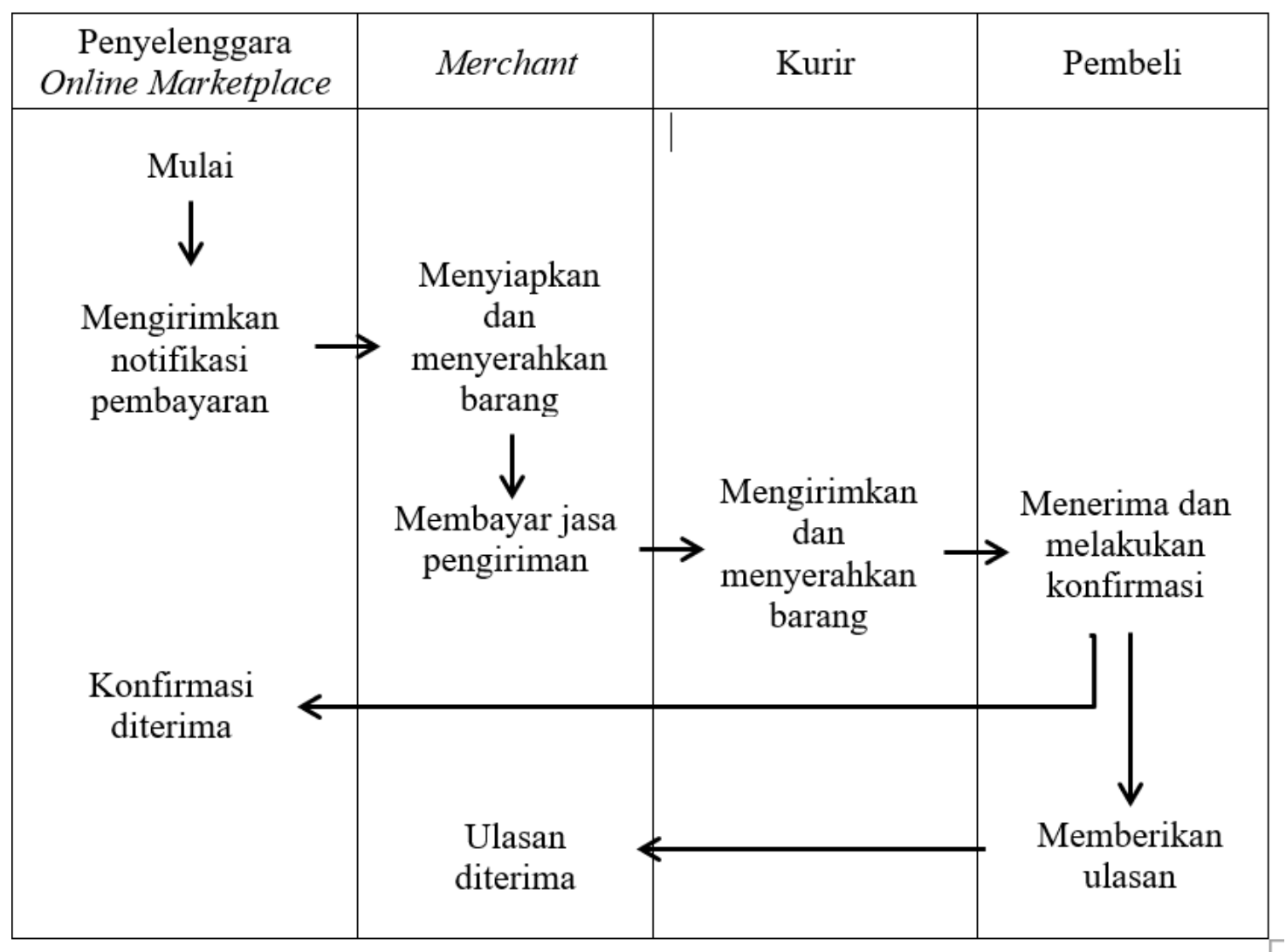

Dalam hal pengiriman, pilihan Kurir disediakan oleh Merchant. Masing-masing Merchant memiliki variasi Kurir yang berbeda. Jenis paket pengiriman pun juga berbeda. Namun, terdapat dua jenis Kurir, yaitu Perusahaan Jasa Pengiriman dan Jasa Antar melalui Transportasi Online. Perbedaan dari keduanya adalah Merchant harus mendatangi tempat Perusahaan Jasa Pengiriman, sedangkan Kurir Transportasi Online akan mendatangi Merchant untuk mengambil barang yang akan dikirim kepada Pembeli. Pembeli harus melakukan konfirmasi melalui aplikasi Tokopedia ketika barang sudah diterima. Hal tersebut dilakukan untuk menyelesaikan transaksi, sehingga pembayaran dapat diteruskan ke Merchant.

\section{Tinjauan Pengenaan Pajak Pertambahan Nilai.}

Pengenaan Pajak Pertambahan Nilai Saat Penyediaan Tempat.

Pada dasarnya Tokopedia menyediakan platform online marketplace secara gratis. Para Merchant dapat membuka toko mereka tanpa dipungut biaya. Proses membuka toko pun sangat mudah. Selain itu, Tokopedia menawarkan fitur premium yang dapat menunjang bisnis para Merchant. Fitur premium yang ditawarkan Tokopedia mengharuskan Merchant untuk membayar imbalan jasa. Imbalan tersebut dapat berupa Monthly Fixed Fee, Rent Fee, Registration Fee, Fixed Fee, atau Subscription Fee. Lebih jelas lagi dalam Lampiran Surat Edaran Direktorat Jenderal Pajak Nomor SE-62/PJ/2013 tentang Penegasan Ketentuan Perpajakan atas Transaksi E-commerce, peristiwa yang berupa jasa penyediaan tempat dan/atau waktu dalam situs internet (Online Marketplace) Tokopedia, yang digunakan untuk mengoperasikan toko, memajang content (kalimat, grafik, video penjelasan, informasi, dan lain lain) barang dan/atau jasa, dan/atau melakukan penjualan. Sehingga fitur premium merupakan objek PPN sebagaimana Pasal 4 ayat (1) huruf c Undang-Undang PPN 1984, yaitu berupa penyerahan Jasa Kena Pajak di dalam Daerah Pabean yang dilakukan oleh Pengusaha, yaitu Tokopedia.

Menurut Lampiran Surat Edaran Direktorat Jenderal Pajak Nomor SE-62/PJ/2013 tentang Penegasan Ketentuan Perpajakan atas Transaksi E-commerce, saat terutang Pajak 


\section{JURNALKU}

Volume 1 No. 1, Maret 2021

Pertambahan Nilai adalah pada saat harga atas penyerahan JKP diakui sebagai piutang atau penghasilan, atau pada saat diterbitkan faktur penjualan oleh Pengusaha Kena Pajak (PKP), sesuai dengan prinsip akuntansi yang berlaku umum dan diterapkan secara konsisten. Sehingga fasilitas Gold Merchant terutang Pajak Pertambahan Nilai saat Merchant membayar biaya langganan ke rekening Tokopedia.

Pengenaan Pajak Pertambahan Nilai Saat Pemesanan Barang.

Pembeli dapat melakukan pembelian barang di Tokopedia dengan mudah. Hanya mencari barang yang dicari kemudian klik "BELI". Kemudian Pembeli hanya mengisi alamat lengkap, jumlah barang yang ingin dibeli, dan Kurir yang akan dipilih. Setelah itu Pembeli akan menerima rincian pembayaran. Setelah melakukan pembayaran, Pembeli tinggal menunggu barang datang.

Menurut Lampiran Surat Edaran Direktorat Jenderal Pajak Nomor SE-62/PJ/2013 tentang Penegasan Ketentuan Perpajakan atas Transaksi E-commerce, objek pajak tersebut adalah penyerahan yang dilakukan oleh Online Marketplace Merchant kepada Pembeli Barang Kena Pajak (BKP) yang dapat berupa penyerahan BKP di dalam Daerah Pabean. Sehingga peristiwa pemesanan barang merupakan objek PPN sebagaimana Pasal 4 ayat (1) huruf a Undang-Undang PPN 1984, yaitu berupa penyerahan Barang Kena Pajak di dalam Daerah Pabean yang dilakukan oleh Pengusaha, yaitu Merchant.

Penyerahan BKP dapat menjadi terutang Pajak Pertambahan Nilai apabila Merchant merupakan Pengusaha Kena Pajak. Di Tokopedia, Merchant berjumlah sangat banyak. Tidak semua Merchant merupakan Pengusaha Kena Pajak. Perlu dilakukan penelitian untuk menentukan Merchant mana saja yang merupakan Pengusaha Kena Pajak. Namun, yang pasti terdapat beberapa dari Merchant di Tokopedia yang merupakan Pengusaha Kena Pajak, yaitu Merchant yang memiliki Official Store.

Selanjutnya, kapan saat pembelian barang tersebut terutang PPN? Menurut Lampiran Surat Edaran Direktorat Jenderal Pajak Nomor SE-62/PJ/2013 tentang Penegasan Ketentuan Perpajakan atas Transaksi E-commerce, saat terutang Pajak Pertambahan Nilai atas peristiwa pembelian tersebut adalah saat pembayaran diterima oleh Penyelenggara Online Marketplace, yaitu Tokopedia. Merchant dapat mengirim barang kepada Pembeli setelah menerima notifikasi pembayaran dari Tokopedia. Oleh karena itu, Faktur Pajak wajib dibuat oleh Merchant saat rincian pembayaran diterima oleh Pembeli melalui aplikasi Tokopedia.

Pengenaan Pajak Pertambahan Nilai Saat Pengiriman Barang.

Ketika Merchant ingin mengirim barang kepada Pembeli, Merchant tidak bisa menyerahkan sendiri kepada Pembeli. Hal tersebut akan merugikan Merchant karena membutuhkan waktu, biaya, dan tenaga yang banyak. Oleh karena itu, Merchant menggunakan Jasa Kurir. Pengenaan PPN atas peristiwa tersebut menurut Lampiran Surat Edaran Direktorat Jenderal Pajak Nomor SE-62/PJ/2013 tentang Penegasan Ketentuan Perpajakan atas Transaksi E-commerce, objek PPN atas peristiwa tersebut adalah penyerahan yang dilakukan oleh Online Marketplace Merchant kepada Pembeli BKP yang berupa penyerahan JKP di dalam Daerah Pabean. Sehingga peristiwa pengiriman barang melalui Kurir merupaka objek PPN sebagaimana Pasal 4 ayat (1) huruf c Undang-Undang PPN 1984, yaitu berupa penyerahan Jasa Kena Pajak di dalam Daerah Pabean yang dilakukan oleh Pengusaha, yaitu Penyedia Jasa Kurir.

Saat terutang PPN atas peristiwa pengiriman barang tersebut adalah saat pembayaran diterima oleh Penyelenggara Online Marketplace, yaitu Tokopedia. Oleh karena itu, Faktur Pajak wajib dibuat oleh Merchant saat rincian pembayaran diterima Pembeli melalui aplikasi Tokopedia. Dasar Pengenaan Pajak (DPP) yang tercantum dalam Faktur Pajak tersebut menggunakan DPP Nilai Lain. Menurut Pasal 2 Keputusan Menteri Keuangan Republik Indonesia Nomor 251/KMK.03/2002 tentang Perubahan atas Keputusan Menteri Keuangan Nomor 567/KMK.04/2000 tentang Nilai Lain sebagai Dasar Pengenaan Pajak, Nilai Lain untuk 


\section{JURNALKU}

Volume 1 No. 1, Maret 2021

Jasa Pengiriman Barang adalah 10\%. Sehingga, DPP sebesar 1\% dari harga jasa pengiriman barang.

\section{PENUTUP}

Tokopedia sebagai salah satu online marketplace di Indonesia memiliki pasar yang besar. Banyak transaksi yang sudah terjadi di online marketplace Tokopedia. Tokopedia mendapatkan penghasilan dari fitur premium yang digunakan oleh Merchant, bukan dari kegiatan pembelian yang dilakukan oleh Pembeli. Peristiwa saat Merchant menggunakan fitur premium Tokopedia merupakan peristiwa yang terutang PPN. Peristiwa saat Merchant yang berstatus PKP menyerahkan barang kepada Pembeli terutang PPN. Invoice atau rincian pembayaran yang diterima Pembeli tidak tercantum telah dikenakan PPN atas pembelian barang. Pembeli melakukan pembayaran kepada Escrow Account yang selanjutnya akan diteruskan kepada Merchant, sehingga Escrow Account wajib memungut PPN dari Pembeli. Peristiwa saat Merchant mengirimkan barang kepada Pembeli menggunakan Jasa Kurir merupakan peristiwa yang terutang PPN. Invoice atau rincian pembayaran yang diterima Pembeli tidak tercantum telah dikenakan PPN atas pemanfaatan Jasa Pengiriman Barang melalui Kurir.

Dari beberapa kesimpulan di atas, atas transaksi-transaksi yang ada di Tokopedia terdapat potensi pajak yang besar. Saat ini pengguna online marketplace Tokopedia sangat banyak. Jika saat ini transaksi-transaksi tersebut belum terutang PPN, maka negara ini kehilangan potensi pajak yang besar pula.

\section{DAFTAR PUSTAKA}

Antariksa, B. (2020). Analisis tingkat kepatuhan pajak atas transaksi online (e-commerce) di Jawa Timur: Studi Kasus Pada Situs Belanja Bukalapak dan Tokopedia (Doctoral dissertation, Universitas Islam Negeri Maulana Malik Ibrahim).

Bagus, D. (2010). E-Commerse: Definisi, Jenis, Tujuan, Manfaat, dan Ancaman Menggunakan E-Commerce. http://jurnal-sdm.blogspot.co.id/2009/08/e-commerse-definisi-jenistujuan.html.

Djufri, M. (2020). Penerapan Teknik Web Scraping Untuk Penggalian Potensi Pajak (Studi Kasus Pada Online Market Place Tokopedia, Shopee Dan Bukalapan). Jurnal BPPK: Badan Pendidikan dan Pelatihan Keuangan, 13(2), 65-75.

Fitriandi, P. (2020). Pemajakan atas Transaksi Melalui Online Marketplace. Jurnal Pajak Indonesia (Indonesian Tax Journal), 4(1), 14-20.

Indriyani, E. K., \& Furqon, I. K. (2021). Analisis Penerapan Pajak Pertambahan Nilai (PPN) Atas Transaksi E-Commerce Pada Platform Marketplace PT. Bukalapak. ASSET: Jurnal Manajemen dan Bisnis, 4(1).

Lukman, E. (2014). 5 Model Bisnis E-commerce di Indonesia. https://id.techinasia.com/5model-bisnis-ecommerce-di-indonesia-2.

Mogi, M. C. (2021). Potensi Dan Hambatan Dalam Pengenaan Pajak Penghasilan Dan Pajak Pertambahan Nilai Terhadap Usaha Berbasis Online (E-Commerce) Di Indonesia. Al Qodiri: Jurnal Pendidikan, Sosial dan Keagamaan, 19(2), 604-615.

Mulya, A. S., \& Agatha, S. V. (2020). Apakah Pajak Pertambahan Nilai Aatas E-Commerce Dapat Diterapkan Di Indonesia?. Journal of Accounting Science and Technology, 1(1).

Nugroho, B. A. F. (2016). Mekanisme Pemungutan Pajak Pertambahan Nilai untuk ECommerce di Indonesia Menggunakan E-Wallet.

Rachmasariningrum, R. (2020). Analisis Yuridis Dampak E-Commerce Terhadap Potensi Kehilangan Pajak Negara Indonesia. Jurnal Civic Hukum, 5(2), 230-241. 


\section{JURNALKU}

Volume 1 No. 1, Maret 2021

Ridho, M. N. (2021). Pengenaan Pajak Pertambahan Nilai (PPN) Pada Transaksi E-Commerce. JISIP (Jurnal Ilmu Sosial dan Pendidikan), 5(1).

Sasana, L. P. W. (2019). Analisis Penerapan Kebijakan Pajak Pertambahan Nilai Atas Transaksi E-Commerce Pada Direktorat Jenderal Pajak. Jurnal Mandiri: Ilmu Pengetahuan, Seni, dan Teknologi, 3(1), 50-66.

Silvia, N. (2019). Aspek Perpajakan Pada Perusahaan E-Commerce PT. XYZ (Doctoral dissertation, Universitas Pembangunan Nasional Veteran Jakarta).

Sukardji, U. (2015). Pokok-Pokok Pajak Pertambahan Nilai Indonesia. Jakarta: PT Rajagrafindo Persada

Wijaya, S., \& Fatimah, Z. (2020). Pajak Atas Parkir Berbayar Badan Layanan Umum. Bina Ekonomi, 24(2), 64-82.

Wijaya, S., \& Nirvana, A. P. (2021). Pajak Pertambahan Nilai Perdagangan Melalui Sistem Elektronik (Studi Kasus PT Shopee Internasional Indonesia). Bilancia: Jurnal Ilmiah Akuntansi, 5(3), 245-256.

Wijaya, S., \& Sabina, D. I. A. (2021). Reformulasi Pengkreditan Pajak Masukan Pasca Omnibus Law. Jurnal Pajak Indonesia (Indonesian Tax Review), 5(1).

Wijaya, S., \& Safira, A. F. (2021). Pajak Penghasilan Atas Anak Angkat Yang Berpenghasilan. Owner: Riset dan Jurnal Akuntansi, 5(2), 396-406.

Wijaya, S., \& Utamawati, H. (2018). Pajak Penghasilan dari Ekonomi Digital atas CrossBoarder Transaction. Jurnal Online Insan Akuntan, 3(2), 135-148. 